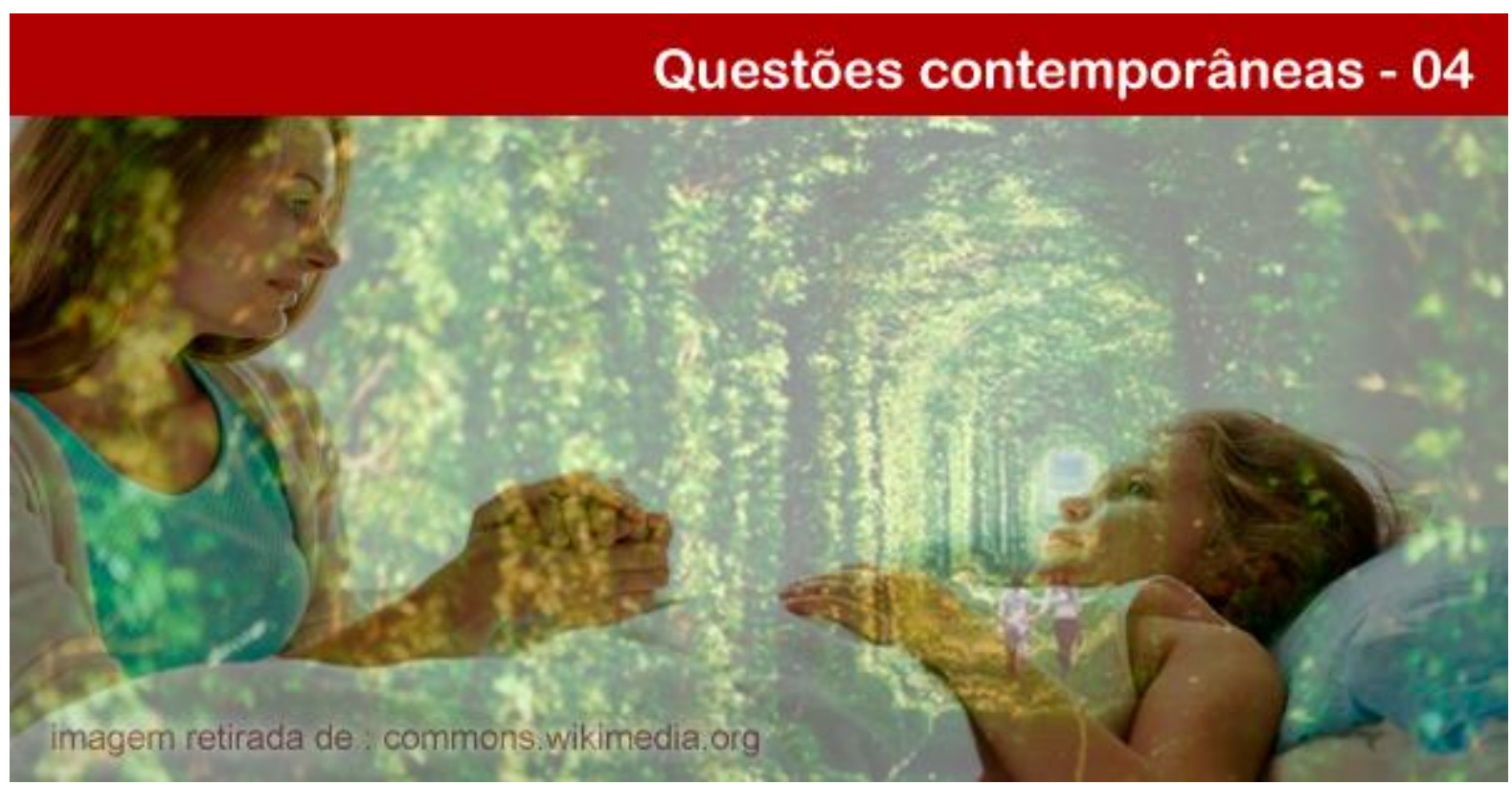

\title{
A MORTE DO OUTRO NÃO É A MINHA, MAS PODE REPRESENTAR O MEU MORRER: REFLEXÕES FENOMENOLÓGICAS
}

\author{
Denilson Aparecida Leite Freire \\ Graduado em Administração e Psicologia. Doutor em Administração. Coordenador do Núcleo de Gestão \\ Estratégica de Pessoas (NGEP) da Universidade Federal de Uberlândia. E-mail: denilson@ufu.br.
}

\author{
Roberta da Costa Borges \\ Graduada em Psicologia. Mestre em Psicologia. Professora das disciplinas de Psicologia Existencial da \\ Faculdade Pitágoras de Uberlândia. E-mail: contato@robertacosta.com.br.
}

Resumo: Objetivando levantar as percepções e representações sobre a morte e o morrer, foi realizada uma pesquisa qualitativa, por meio de entrevista, seguida por um grupo focal, com alunos do curso de Psicologia de uma universidade privada do triângulo mineiro. As investigações fenomenológicas demonstraram um possível percurso rumo à busca da autenticidade, segundo Heidegger (1996), metaforicamente indo da luz (negação por meio da crença além morte), passando para sombra (evitação da dor e sofrimento), espelhando a própria morte (reconhecendo o seu próprio morrer) até ao nada e a possibilidade de refletir sobre as ilusões vivenciadas para evitar a própria morte, silenciando-as e libertando o homem para escolhas autênticas. Os estudos revelaram ainda a importância do cuidar e o fazer diante da morte, explicitando a importância de se vivenciar o luto e a preparação do homem para lidar com sua finitude. Assim, o luto deve ser mais humanizado e menos banal, devendo ser respeitada a dor do outro, mas sem buscar atalhos para essa dor. É buscar acolhimento, eliminar a culpa social, revelando os novos sentidos que o processo poderá trazer na vida de quem fica. Esse deveria ser o verdadeiro papel das pessoas diante da morte e do morrer.

Palavras chaves: Percepção de Morte. Método Fenomenológico. Autenticidade.

\section{THE DEATH FROM THE OTHER IS NOT MY, BUT CAN REPRESENT MY DYING: PHENOMENOLOGICAL REFLECTIONS}

Abstract: Aiming to raise the perceptions and representations of death and dying, a qualitative research was carried out through interviews, followed by a focus group with students of Psychology of a private university in the Brazil. Phenomenological investigations showed a possible route towards the pursuit of authenticity, according Heidegger (1996) metaphorically going light (denial through belief beyond death), passing shadow

\section{POLÊM!CA LABORE (}

Polêmica - Revista Eletrônica da Uerj - Rua São Francisco Xavier, 524, $1^{\circ}$ andar

bloco D, sl.1001 • Tels.: +55 21 2334-4088/4087 • http://www.e-publicacoes.uerj.br/index.php/polemica/index http://www.labore.uerj.br • laboreuerj@yahoo.com.br 
(avoidance of pain and suffering), mirroring his own death (recognizing his own death) to the nothing and the ability to reflect on the lived illusions to avoid his own death, silencing them and releasing the man to authentic choices. The studies also revealed the importance of care and make the face of death, explaining the importance of experiencing grief and preparation of man to handle his finitude. Thus, the fight should be more humane and less banal and should be respected the other's pain, but without seeking shortcuts to this pain. It is seeking host, eliminating social guilt, revealing new ways that the process can bring the lives of those who stay. This should be the real role of people facing death and dying.

Keywords: Death Perception. Phenomenological method. Authenticity.

\section{Introdução}

A percepção sobre a morte se modificou muito nas últimas décadas. Segundo Caputo (2008) a partir do século XX não se morre mais com a família, mas em hospitais, assim como o velório também deixa as salas dos lares para locais afastados da cidade, tudo com a intenção de diminuir essas experiências com a morte, tornando-a um tabu.

Tem-se visto, também, o encurtamento das cerimônias de sepultamento, assim como ocorreu com os períodos de luto, cada vez menores e inexpressivos. A sociedade passou a privilegiar a preservação da felicidade e evitar vivenciar as experiências de morte (CAPUTO, 2008).

Mas será que esses novos comportamentos podem evitar, do ponto de vista psicológico, a dor e deixar com que aqueles que foram tocados pela morte imunes a ela? Esse artigo teve por objetivo, então, investigar quais são as percepções atuais dos jovens sobre a morte e o morrer e quais são as possíveis consequências psicológicas dessas visões sobre a vida deles.

Foi escolhido o método fenomenológico de pesquisa, pois, segundo Lanigan (1988) ele permite que o homem expresse suas experiências com o mundo, partindo do pressuposto que é na relação do homem com o mundo que ele se constrói e é construído, possibilitando, por meio das suas representações, das suas vivências, compreender como se dão tais relações. É na relação do homem com o mundo que ele se revela (HEIDEGGER, 1988).

A pesquisa se deu em dois momentos distintos, um caracterizado pela entrevista a vinte e dois alunos do curso de psicologia de uma faculdade do Triângulo Mineiro e outro caracterizado pela condução de um grupo focal com oito alunos para aprofundar as percepções sobre o tema.

A seguir está apresentado o marco teórico que fundamenta esse artigo, seguida pela explicação de como se deu a metodologia de pesquisa e a análise fenomenológica dos resultados.

\section{POLÊM!CA $\mid$ LABORE}


Espera-se que esses achados possam contribuir para uma melhor compreensão da visão sobre a morte e o morrer desses jovens na atualidade e as possíveis repercussões psicológicas nas suas vivências. Poderá contribuir também para o aprofundamento dos estudos fenomenológicos sobre a morte e o morrer, possibilitando insights que possam ser utilizados tanto no ensino quanto na pesquisa sobre esse tema.

\section{A Morte e o Morrer: uma breve concepção}

Segundo Ariès (2003), durante a Idade Média a morte fazia parte do contexto familiar. Os ritos de passagem eram estruturados publicamente e planejados previamente pelo próprio moribundo. Nesse sentido, ele era consciente da sua finitude em uma época marcada pelas doenças. Contudo, na Idade Moderna, a morte tornou-se romantizada, uma ruptura entre o cotidiano e o além. Com isso, os sepultamentos deixam as casas e as igrejas e se dão em cemitérios, afastados das cidades, afastados da vivência humana, dicotomizando a vida e a morte. Assim, a morte não é a de si mesmo, mas a do outro (CAPUTO, 2008).

Tem-se nos séculos XX e XXI a morte e o morrer como sinônimo de fracasso, de uma ruptura da felicidade, da não conquista da plenitude. Isso levou as pessoas a terem um olhar temeroso sobre o tema, afastando-o de si, afastando-o da sua felicidade, o que pode contribuir para implicações psicológicas (CAPUTO, 2008).

Kübler-Ross (1996) afirmava que era inconcebível para o homem imaginar um fim real para a vida terrena e que, se essa tem um fim, foi devido a uma intervenção maligna. Assim, segundo essa autora, a morte sempre esteve associada a algo negativo. E, com o avanço da tecnologia e das conquistas científicas os homens tornaram-se capazes de construir armas de destruição de massa, o que aumentou o temor diante da morte, levando o homem a se defender dessa finitude, negando-a enquanto pode. Outros alegam acreditar na vida após a morte, o que talvez seja, na visão da autora, uma negação da própria mortalidade.

Em seus seminários sobre a morte e o morrer, Kübler-Ross (1996) apontou cinco atitudes do homem durante o luto, que são: negação, raiva, barganha (negociação), depressão e aceitação. Observa-se que o primeiro estágio é negar o contato com a morte, evitando-a e contribuindo para criar diferentes visões sobre ela. Tem-se, com isso, diferentes comportamentos e atitudes frente à morte. Spilka et al. (1977) sugerem que os estudos sobre as percepções de morte podem ser agrupados em oito dimensões:

\section{POLÊM!CA $\mid$ LABORE}


1. Dor e solidão: representa a morte como um momento de agonia, isolamento, miséria, angústia e solidão.

2. Vida do além: aponta uma imagem da morte como uma nova vida, plena de satisfação, felicidade, recompensa e união com Deus.

3. Indiferença: indica a morte como um fenômeno indiferente ao ser humano.

4. Desconhecida: apresenta a perspectiva da morte como incerteza, mistério e desconhecimento.

5. Abandono: imagina a morte como o abandono de entes queridos e como um momento para se sentir culpado.

6. Coragem: concebe a morte como uma oportunidade para demonstrar virtudes, no caso, enfrentar o último teste da vida.

7. Fracasso: indica a morte como algo que impede a realização do potencial pessoal, por exemplo, a realização de objetivos e sentido da vida.

8. Fim natural: sugere a morte como algo que faz parte do ciclo natural da vida.

Para Heidegger (1997), todo momento existencial é afetado pela morte, constituindo o homem em um "ser-para-a-morte" (Sein zum Tode). E é diante dessa certeza que ele pode escolher evitá-la, se fazendo indiferente diante do inevitável, como a grande maioria, ou encará-la, aceitando todas as condições trazidas por elas, tornando-se um ser livre.

A questão da constituição ontológica de 'fim' e 'totalidade', obriga a tarefa de uma análise positiva dos fenômenos da existência até aqui postergados. No centro destas considerações, acha-se a caracterização ontológica do ser-para-o-fim em sentido próprio da presença e a conquista de um conceito existencial da morte. (HEIDEGGER, 1997, p. 17).

Assim, segundo Heidgger (1997) é diante do ser-para-a-morte que o Dasein é impulsionado a decidir-se perante as demais possibilidades que se apresentam, escolhendo qual modo deverá de existir, pois ao chegar à morte, toda possibilidade será definitivamente retirada sejam elas quaisquer que sejam. Resumidamente, tem-se que o viver para a morte, então, é o autêntico sentido da existência, pois afasta o homem da simples submissão aos fatos e circunstâncias cotidianas, libertando-o das suas próprias ilusões.

\section{Método Fenomenológico}

\section{POLÊM!CA $\mid$ LABORE}


O pensamento fenomenológico existencial parte do pressuposto de que o homem se constitui com ser-no-mundo. Isso implica em afirmar que o homem, desde o seu primórdio, se revela na sua relação com o mundo (HEIDEGGER, 1988).

$\mathrm{Na}$ relação com o mundo, o homem passa ter suas experiências conscientes que ocorrem por meio das significações que faz dos acontecimentos que constituem tais vivências. Assim, todas as experiências constituem-se e expressam-se no próprio homem (LANIGAN, 1988) sendo possível, através do método fenomenológico, que esse ser expresse suas experiências com o mundo.

Pode-se então afirmar que a experiência consciente é um ato comunicativo de um ser situado em um determinado contexto histórico e social e que pode ser apreendida pela linguagem. Assim, como meio de investigação foi utilizada a entrevista e o grupo focal como ferramentas para facilitar a apreensão dos sentidos de morte pelos participantes. A entrevista favorece a exploração de um fenômeno e o sentido que ele traz para a vivência dos sujeitos pesquisados. Já a técnica de grupo focal constitui-se em um debate aberto com a reunião de diferentes participantes em torno de um tema em comum, onde as diferenças de status não são levadas em consideração (GASKELL, 2002).

A análise das experiências relatadas tanto na entrevista e no grupo focal, basearam-se no método fenomenológico proposto por Husserl (1992) que estabeleceu três passos reflexivos para o estudo da experiência consciente (GOMES, 1998):

- Descrição: nessa etapa procura-se relatar o fenômeno estudado na vivência dos próprios participantes, de modo direto e sem nenhuma avaliação.

- Análise indutiva: nessa etapa são escolhidas partes das descrições que se mostrem fundamentais para compreensão do fenômeno que se quer estudar. Essa escolha ocorre por meio da técnica de variação imaginativa livre e por meio do questionamento dos relatos dos participantes, enfatizando as descrições consideradas essenciais para explicação do fenômeno investigado.

- Análise crítica: nessa etapa são propostas uma possível compreensão do fenômeno estudado.

Dessa forma, a primeira etapa, a da entrevista, ocorreu em três momentos: a escolha dos participantes, a sensibilização para a entrevista e a entrevista propriamente dita. A escolha dos participantes foi feita de forma intencional, ou seja, foram escolhidos alunos do curso de

\section{POLÊM!CA $\mid$ LABORE}


graduação em psicologia que estivessem cursando a disciplina sobre Psicologia Hospitalar. Essa escolha se deu porque tais alunos estão sendo preparados para lidar com as angústias do ser humano, contribuindo para vivenciarem com maior sensibilidade o fenômeno da morte proposto. Influenciou a escolha o fato de terem cursado a disciplina de Psicologia Hospitalar em que são tratados tópicos sobre a morte e o morrer, preparando-os para lidarem com essas situações na vida profissional. Em seguida, no momento de sensibilização, os alunos foram convidados a assistirem ao filme intitulado: Minha vida sem mim $^{1}$. Após assistirem ao filme foram convidados a relatarem suas experiências guiadas por quatro perguntas iniciais e que deveriam ser descritas por escrito:

1. Qual cena, parte ou imagem do filme mais te marcou? Por quê?

2. O que você faria se tivesse pouco tempo de vida?

3. Qual o sentido da morte para as pessoas em geral? E para você?

4. Você acredita que os rituais são importantes na morte?

No formulário de entrevista havia campos para identificação do gênero, faixa etária, estado civil, número de filhos, classe social e religião, para traçar um breve perfil desses participantes. Dessa etapa participaram 22 discentes.

Em seguida foram convidados 8 participantes, de forma voluntária e que estavam presentes na primeira fase da pesquisa para participarem de um grupo focal, objetivando aprofundar a análise qualitativa sobre as reflexões sobre a morte e o morrer. As reflexões foram conduzidas a partir de cinco questões norteadoras:

1. Qual a principal reflexão que o filme nos traz?

2. Você percebe mudanças, desde o tempo dos seus avós até hoje, em como as pessoas lidam com a morte?

3. As pessoas estão preparadas para lidar com a morte?

4. Quais são os principais obstáculos, nos dias de hoje, para se falar da morte?

5. Na sua opinião, como as pessoas deveriam lidar com a morte? Qual o papel do Psicólogo nesse contexto?

O debate foi gravado com a autorização dos participantes. Ao final foi feita a transcrição dos diálogos e realizada análise de conteúdo.

\footnotetext{
${ }^{1}$ Filme espanhol e canadense lançado em 2003, a partir de um conto de Nanci Kincaid sobre a direção de Isabel Coixet e que trata da vida de Ann (Sarah Polley), mãe de duas meninas e, que descobre que possui câncer terminal.
}

\section{POLÊM!CA $\mid$ LABORE}




\section{Análise dos Resultados}

Nessa seção estão apresentados os dados e as análises fenomenológicas existenciais. Inicialmente, são apresentados o perfil dos entrevistados, em seguida uma análise das questões realizadas na etapa das entrevistas e, finalmente, a análise das experiências reveladas por eles, no grupo focal.

\section{$\underline{\text { Perfil dos Pesquisados }}$}

No Quadro 1 encontra-se a relação dos participantes que assistiram ao filme e participaram da enquete, via entrevista, sobre a morte e o morrer.

Quadro - 1: Identificação dos Participantes

\begin{tabular}{|c|c|c|c|c|c|c|c|}
\hline Indivíduo & Sexo & Idade & Conjugal & Filhos & Classe & Convive & Religião \\
\hline 1 & F & 37 & Casado & Sim & Média & Cônjuge & Evangélica \\
\hline 2 & F & 22 & Casado & Não & Média & Cônjuge & Evangélica \\
\hline 3 & F & 27 & Solteiro & Não & Média & Amigos/Colegas & Evangélica \\
\hline 4 & F & 32 & Solteiro & Não & Média & Pais & Católica \\
\hline 5 & F & 38 & Casado & Sim & Baixa & Cônjuge & Evangélica \\
\hline 6 & F & 46 & Casado & Sim & Média/Baixa & Cônjuge & Católica \\
\hline 7 & F & 55 & Casado & Sim & Média & Cônjuge/Filhos & Católica \\
\hline 8 & F & 21 & Solteiro & Não & Média & Namorado (a) & Católica \\
\hline 9 & F & 22 & Casado & Sim & Baixa & Cônjuge & Católica \\
\hline 10 & F & 24 & Solteiro & - & Média/Baixa & Sozinho(a) & Católica \\
\hline 11 & F & 36 & Casado & Não & Média & Cônjuge & Católica \\
\hline 12 & F & 34 & Casado & Sim & Média/Baixa & Filhos & Não \\
\hline 13 & M & 27 & Casado & Sim & Média/Baixa & Cônjuge/Filhos & Não \\
\hline 14 & F & 27 & Casado & Não & Média/Baixa & Cônjuge & Evangélica \\
\hline 15 & F & 22 & Solteiro & Não & Média/Baixa & Pais & Espírita \\
\hline 16 & F & 28 & Solteiro & Não & Média & Amigos/Colegas & Não \\
\hline 17 & F & 22 & Solteiro & Não & Média & Pais & Católica \\
\hline 18 & F & 47 & Outro & Sim & Média & Sozinho(a) & Todas \\
\hline 19 & M & 26 & Casado & Não & Média/Baixa & Cônjuge & Evangélica \\
\hline 20 & M & 56 & Outro & Sim & Média & Namorado (a) & Espírita \\
\hline 22 & F & 30 & Casado & Não & Média/Baixa & Cônjuge & Católica \\
\hline
\end{tabular}

Fonte: Os Autores.

\section{POLÊM!CA $\mid$ LABORE}

Polêmica - Revista Eletrônica da Uerj - Rua São Francisco Xavier, 524, $1^{\circ}$ andar bloco D, sl.1001 • Tels.: +55 21 2334-4088/4087 • http://www.e-publicacoes.uerj.br/index.php/polemica/index http://www.labore.uerj.br • laboreuerj@yahoo.com.br 
Essa relação de perfis se faz importante porque, durante a análise dos resultados, algumas falas serão identificadas pela numeração corresponde a cada participante nas categorias analisadas.

O perfil dos entrevistados está expresso, também, em quantidade absoluta, na Tabela 1.

Observa-se que a maioria dos entrevistados é do sexo feminino (muito em função da especificidade de gênero presente no curso de psicologia), com idade média de 21 a 30 anos, portanto, mais jovens, entretanto, a maioria já se encontra casada.

Verifica-se, também, que a metade dos entrevistados possuem filhos e residem com seus cônjuges, e são da classe média. Em relação à religião, houve a presença das mais representativas na sociedade brasileira, com predominância do catolicismo.

Tabela - 1: Perfil dos Entrevistados

\begin{tabular}{|c|c|c|}
\hline Variáveis & Detalhamento & Quantidade \\
\hline \multirow[t]{2}{*}{ Sexo } & Masculino & 3 \\
\hline & Feminino & 19 \\
\hline \multirow[t]{3}{*}{ Faixa etária } & 21 a 30 & 12 \\
\hline & 31 a 40 & 6 \\
\hline & 41 a 60 & 4 \\
\hline \multirow[t]{3}{*}{ Estado Civil } & Solteiro & 7 \\
\hline & Casado & 13 \\
\hline & Outros & 2 \\
\hline \multirow[t]{2}{*}{ Filhos } & Sim & 11 \\
\hline & Não & 11 \\
\hline \multirow[t]{6}{*}{ Reside com } & Amigos & 2 \\
\hline & Cônjuge & 11 \\
\hline & Filho & 1 \\
\hline & Namorado & 2 \\
\hline & Pais & 3 \\
\hline & Sozinho & 3 \\
\hline \multirow[t]{3}{*}{ Classe social } & Baixa & 2 \\
\hline & Média/Baixa & 9 \\
\hline & Média & 11 \\
\hline \multirow[t]{5}{*}{ Religião } & Católica & 9 \\
\hline & Espírita & 3 \\
\hline & Evangélica & 6 \\
\hline & Não tem & 3 \\
\hline & Todas & 1 \\
\hline
\end{tabular}

Fonte: Os Autores.

\section{POLÊM!CA LABORE}


Todas essas variáveis podem afetar o sentimento, a visão sobre a morte e o morrer, bem como as experiências de cada um. Nesse sentido, esse trabalho não se preocupou em estabelecer correspondências segundo gênero, idade, dentre outros, mas buscou ter uma amostragem o mais diversa possível para apurar as diferentes percepções sobre o tema.

\section{$\underline{\text { Análise das Entrevistas }}$}

Analisando-se as respostas dos participantes, pode-se categorizar as afirmativas dos participantes em cinco dimensões, a fim de análise, que são: a percepção da finitude, as representações da morte, o sentido da morte, os rituais e o cuidar na morte.

\section{A Percepção da Finitude}

Buscou-se, na fala dos participantes, compreender como eles vivenciam a noção da finitude, isso é, de saber que o homem possui um limite tempo-espacial da sua existência. Como afirmava Heidegger (1997), o homem caminha para morte, ele é "um ser-para-amorte".

Primeiramente, percebeu-se que falar da morte traz um certo desconforto, pois os participantes entram em contato com sua própria finitude. Ninguém quer falar porque "... $a$ morte escancara que você é finito, um dia vai morrer" (Participante 4). Essa idéia foi logo complementada pelo participante 14 que disse que "... a morte tira o poder do homem, mostrando sua fragilidade e mortalidade." Observa-se que as primeiras falas são carregadas de defesa, e que as pessoas em geral tentam evitar falar do tema para não entrar em contato com a sua própria morte. Assim, segundo o participante 12, "... a morte é um grande tabu, igual ao sexo", revelando a complexidade em se falar desse tema e o processo de negação que ele traz.

Entretanto, apesar do processo de negação, alguns participantes (1 e 20) defenderam que não tinham problemas em se perceber finito. Como disseram: "... para alguns a morte não é o fim, mas uma transição, como para os espíritas e budistas". Entretanto, apostar na religião ou na espiritualidade, acreditar em um pós-morte, em uma existência para além do morrer, também não é uma fuga para não se aceitar a sua própria finitude e se considerar eterno? Assim, infere-se que diante da certeza da morte, o homem possui duas atitudes: ou

\section{POLÊM!CA $\mid$ LABORE}


escolhe encará-la, aceitando sua condição finita e/ou se faz de indiferente, negando e buscando formas de adiar a morte. Giles (1989) afirmou que nessa fuga diante da morte, mais uma vez o ser-aí retira de si toda a capacidade de decisão autêntica e toda a responsabilidade própria, levando-o a viver uma atitude de fuga constante, como fizeram os entrevistados.

A angústia, portanto, não é o medo da morte, mas é a percepção profunda da finitude (do morrer). Somos o único ser capaz de reconhecer que existimos para morrer. Uma atitude autêntica, segundo Giles (1989), seria confrontar a morte, lidar com essa finitude e experienciar a angústia da morte, libertando-se.

\section{As Representações da Morte}

Ao se fazer uma analogia da morte dos outros, por meio da análise fílmica e aplicar essa vivência a si mesmo, viu-se que a morte de outros é o fim do mundo deles: "em sentido genuíno, não fazemos a experiência da morte dos outros, no máximo, estamos apenas juntos" (HEIDEGGER, 1997, p. 19). É nesse estar junto que compreende-se que a morte será apenas uma lembrança para os que permanecem. Tais lembranças desencadearam reflexões que levaram a identificação de quatro vivências distintas pelos participantes: identificação, evitação, conformidade e transcendência. Isso não quer dizer que são somente essas experiências que podem ser vivenciadas pela população em geral, mas foram as que mais se destacaram no grupo de controle.

Os participantes que se identificaram com a morte do outro são aqueles que tiveram perdas significativas e que o filme os fez reviver diferentes sentimentos diante da perda. No processo de evitação, os participantes demonstraram certa aversão ao falar da morte, negando, assim, a possibilidade de um contato íntimo com o tema, seja por medo, preconceito ou descaso com a morte daquele outro que não se relaciona com o participante. Já na conformidade, os participantes compreenderam o processo da morte do outro como um processo natural e inevitável e afirmaram que todo ser caminha para a morte, para o nada. Finalmente, outros transcenderam ao tema, acreditando numa dimensão pós-morte, o que justificaria o alto nível de "aceitação" demonstrada diante do fenômeno.

No Quadro 2 estão algumas falas dos participantes que justificam a classificação sugerida para categorização das representações sobre a morte.

\section{POLÊM!CA $\mid$ LABORE}


Analisando-se essas representações, observa-se que elas nos remetem às duas atitudes propostas por Giles (1989) de encarar ou não sua própria finitude. As representações de Sombra (negação) e Luz (Transcedência) remetem à atitude de se fazer indiferente na presença do que é inevitável, de ser inautêntico diante da sua finitude, do seu próprio morrer. Tais representações criam ilusões de que a morte não existe no universo do ser (sombra) ou de que será eterno, vencendo a própria morte (transcendência).

Assim, essas pessoas criam falsas ilusões para evitarem a morte. Muitos preenchem o vazio com divertimentos e consumismo, buscam cargos de poder, dinheiro, sexo, tudo para fugir da angústia e da responsabilidade por suas vidas.

Quadro - 2: Representações sobre a Morte: Imagens Geradoras

\begin{tabular}{|c|c|c|}
\hline Processo & Representação $^{2}$ & Afirmativas e Argumentos dos Participantes \\
\hline Evitação & $\begin{array}{l}\text { A Sombra: A morte do outro } \\
\text { revela, em mim, sentimentos } \\
\text { aversivos que devem ser } \\
\text { evitados. A morte deve ser } \\
\text { emudecida nas sombras. } \\
\text { "... ninguém quer falar da } \\
\text { morte, é algo sombrio e } \\
\text { assustador". (Participante 12) }\end{array}$ & $\begin{array}{l}\text { ".... uma cena marcante é quando a personagem está } \\
\text { em um supermercado e ela sofrendo ou pensando } \\
\text { que vai morrer e de repente vê as pessoas todas } \\
\text { felizes, dançando. Ela percebe então o quanto as } \\
\text { pessoas ficam nas ilusões para evitar a morte. O } \\
\text { consumismo, os bens materiais, tudo para que a } \\
\text { pessoa tenha uma falsa felicidade e evite pensar na } \\
\text { morte." (Participante 9) } \\
\text { "... ninguém gosta de falar da morte... ninguém está } \\
\text { preparado para morrer...aprendemos que temos que } \\
\text { sobreviver a cada dia e evitar, ao máximo a morte" } \\
\text { (Participante 12). }\end{array}$ \\
\hline Transcendência & $\begin{array}{l}\text { A Luz: A morte é apenas uma } \\
\text { transição para outra realidade. } \\
\text { "... a vida não termina e } \\
\text { quando morremos, todos } \\
\text { buscam uma } \underline{\text { luz ao final do }} \\
\text { túnel. (Participante 20) }\end{array}$ & $\begin{array}{l}\text { "... não sei por que as pessoas não sabem lidar com a } \\
\text { morte! Há pessoas espíritas, budistas que estão } \\
\text { preparados para o morrer. Para eles a morte é apenas } \\
\text { uma passagem, uma mudança de um estado para } \\
\text { outro." (Participante } 1 \text { ) } \\
\text { "... Cada um tem a sua hora, o difícil não é morrer, } \\
\text { mas encarar o que vem depois."(Participante } 20) \text {. }\end{array}$ \\
\hline Identificação & $\begin{array}{l}\text { O Espelho: a morte do outro } \\
\text { se identifica com as "minhas } \\
\text { mortes" } \\
\text { "... a morte reflete nosso } \\
\text { próprio fim." (Participante 17) }\end{array}$ & $\begin{array}{l}\text { "... fico pensando nas coincidências da vida, né? Tem } \\
\text { elementos que sempre se repetem, assim como meu } \\
\text { sofrimento. Então, assim como no filme, na data que } \\
\text { meu filho faria aniversário (morto há mais ou menos } \\
\text { dois anos), eu encontrei um e-mail onde ele dizia que } \\
\text { me amava.." (Participante 17) } \\
\text { "... existe diferenças entre a morte e o morrer, falar } \\
\text { dela pode até ser fácil, mas vivenciar, estar diante do } \\
\text { morrer nos leva a refletir sobre nossa própria vida e } \\
\text { de que como vamos morrer." (Participante 15) }\end{array}$ \\
\hline Conformidade & $\begin{array}{l}\text { O Nada: A morte do outro é } \\
\text { um processo natural e } \\
\text { inevitável. Todos caminham } \\
\text { para a morte, para o nada. }\end{array}$ & $\begin{array}{l}\text { "... não concordo com a personagem do filme, gravar } \\
\text { fitas para os aniversários da filha. Isso é trazer de } \\
\text { novo o sofrimento a cada ano. Morreu, acabou e } \\
\text { pronto! (Participante 4) }\end{array}$ \\
\hline
\end{tabular}

${ }^{2}$ A representação foi criada por meio das imagens reveladas pelos participantes da pesquisa.

\section{POLÊM!CA LABORË}

Polêmica - Revista Eletrônica da Uerj - Rua São Francisco Xavier, 524, $1^{\circ}$ andar

bloco D, sl.1001 • Tels.: +55 21 2334-4088 / 4087 • http://www.e-publicacoes.uerj.br/index.php/polemica/index http://www.labore.uerj.br • laboreuerj@yahoo.com.br 


\begin{tabular}{|l|l|l|}
\hline & $\begin{array}{l}\text { "... todos vamos morrer, faz } \\
\text { parte da vida, não tem por que } \\
\text { sofrer antecipadamente, somos } \\
\text { somente carne, somos um } \\
\text { nada. } \text { (Participante 14) }\end{array}$ & $\begin{array}{l}\text { "... não acredito em vida pós morte... para mim, } \\
\text { nõre é acabou tuda, fica inventado comem não entende que ele } \\
\text { as religiões." (Participante 14). }\end{array}$ \\
\hline
\end{tabular}

Fonte: Os autores.

Já as representações do Espelho (identificação) e do Nada (conformidade) levam a uma atitude de reconhecer a sua própria finitude, de compreender que o homem é um ser que caminha para a morte. Para Heidegger (1996),

O nada é a possibilidade da revelação do ente enquanto tal para o ser-ai humano. $\mathrm{O}$ nada não é um conceito oposto ao ente, mas pertence originariamente a essência mesma (do ser) (HEIDEGGER, 1996, p. 59).

Assim, o nada é o véu do ser (GILLES, 1989). Ele se manifesta em nossa existência mostrando que tudo se aniquila diante do nada, revelando que o homem é um ser para a morte e levando o homem à autenticidade, termo aqui utilizado no sentido de expressar que o homem passa a se apropriar das suas próprias questões e a se responsabilizar por seu próprio existir.

A análise dessas representações revela um processo que vai da inautenticidade à autenticidade, isso é, indo da não aceitação à apropriação da finitude humana. Assim, para fins didáticos, pode-se graduar as representações em relação à autenticidade, como mostra a Figura 1.

Figura - 1: O processo de Aceitação (Autenticidade) diante da Finitude (do morrer)

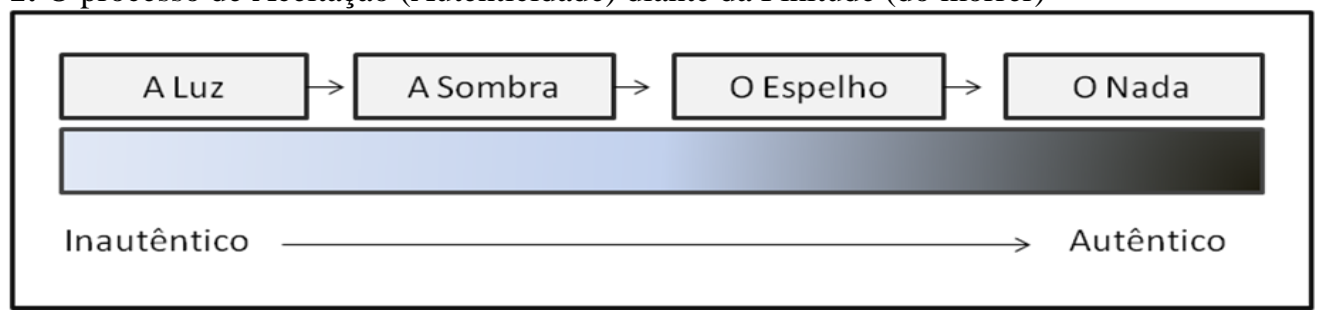

Fonte: Os autores.

Como mostra a Figura 1, a representação da Luz demonstraria a negação da finitude por meio da crença da eternidade do homem, em uma vida pós-morte. Na sombra, vê-se a negação do morrer, como algo distante a acontecer. Já no espelho, inicia-se uma tomada de

\section{POLÊM!CA $\mid$ LABORE}

Polêmica - Revista Eletrônica da Uerj - Rua São Francisco Xavier, 524, $1^{\circ}$ andar bloco D, sl.1001 • Tels.: +55 21 2334-4088/4087 • http://www.e-publicacoes.uerj.br/index.php/polemica/index http://www.labore.uerj.br • laboreuerj@yahoo.com.br 
consciência do próprio morrer e na representação do Nada, o homem percebe-se, conscientemente, da sua própria finitude.

\section{O Sentido da Morte}

Quando convidados a refletir que, tomada a consciência de que o homem é um serpara-a-morte, qual deveria ser ou se teria, algum sentido na morte, os participantes descreveram alguns possíveis sentidos. Nesse momento, os pesquisadores focaram nas falas dos participantes que representaram a morte enquanto Espelho e Nada, uma vez que os que a representaram como Luz, indicaram que a morte é apenas uma passagem para outra vida, logo o sentido seria de transição; e os que a representaram como Sombra, afirmaram não verem sentido na morte, já que traz apenas angústia e sofrimento.

Descreveram, assim, vários sentidos que a percepção da finitude pode despertar. Os participarem chegaram à conclusão de que "... o problema não é morrer, mas morrer sem ter vivido" (fala do participante 20 com concordância de vários outros). Isso leva a inferir que se uma pessoa teve uma vida autêntica, livre e responsável, ela morreria mais realizada, enquanto que aquela que permaneceu nas ilusões teria mais dificuldade de aceitar sem fim ou de aceitar que sempre viveu o que a sociedade lhe exigia e não o que realmente queria. A percepção da morte, então, revelaria tais ilusões, levando o homem à apropriação da sua própria finitude. Isso pode ser visto na fala de uma participante 17:

\footnotetext{
"O que me chamou a atenção no filme foi a cena em que ela [a personagem] estava na chuva, sentindo a chuva e com os pés na grama. Então...ela sabia que ia morrer...e estava curtindo aquele momento. Assim... quando a morte se aproxima, a pessoa sacode, né? Faz com que ela saia do automático da vida. A pessoa para de ficar zumbizando..."
}

Então, a consciência da morte, retira a pessoa do "automático", isso é, de tudo aquilo que ela considerava como importante, como um bom emprego, riquezas, bens materiais, tudo aquilo que ela criou para fugir da própria morte, e a faz repensar no que realmente teria significado para ela. Um outro participante lembrou da cena do filme em que a personagem estava em um supermercado e, de repente, ela percebeu o quanto as pessoas estavam iludidas com suas próprias vidas, consumindo, comprando roupas e presentes caros. As pessoas começaram uma verdadeira dança dentro do supermercado, demonstrando sua felicidade, enquanto que a personagem sabia da realidade, isso é, que todos estavam apenas iludidos. A

\section{POLÊM!CA $\mid$ LABORE}


personagem estava, segundo um dos participantes (não identificado) "...com o olhar desiludido que a morte traz." Essa desilusão não deve ser encarada como pejorativa, como no senso comum que acreditamos que a desilusão é algo ruim. Na fenomenologia, a desilusão é entrar em contato com a realidade, é retirar os véus, as ilusões que nos afastam de nós mesmos.

Um dos participantes (20) contou como mudou de visão sobre a morte, após o falecimento do pai. Ele disse que

\footnotetext{
"...quando meu pai morreu eu mudei a forma de ver as pessoas e o mundo... eu acho que era egoísta, só pensava em mim mesmo, mas depois, né, quando ele morreu, vi o mundo como um lugar perigoso e por isso hoje ajo com mais cautela, sou mais atencioso com minha mãe e com as pessoas."
}

Dessa forma, pode-se concluir que o verdadeiro sentido da morte, como disse esse participante, é que ela "traz novas ressignificações" para a vida, retirando as ilusões e levando o homem a se apropriar daquilo que realmente traz sentido ao seu viver.

Segundo Souza (2015), a vida autêntica surge quando o homem é capaz de dar sentido à sua vida, preenchendo o nada que ele próprio é. A vida não tem um sentido, ela é um eterno vazio. Assim, é o homem que deve preenchê-la, norteá-la. O sentido será dado pelas escolhas de cada um e é por meio delas que ele vai preenchendo esse nada que é, criando uma biografia, uma história, um sentido para sua vida.

\section{Os Rituais na Morte}

Se a morte pode trazer uma reflexão no sentido da vida, o que se tem na contemporaneidade é o predomínio das representações da morte enquanto Luz e Sombra. O homem moderno procura negar a experiência de morte, em busca eterna da felicidade. Com isso, houve uma mudança nos próprios rituais da morte.

Segundo Caputo (2008), a partir do século XII, a morte deixa de ser vista como um processo natural e passa a ser tida como um processo de provação, assim o corpo deixa de ser familiar para se tornar algo insuportável, devendo ser ocultado em caixas (caixões) e, na modernidade, o homem passa a ver a morte como uma ruptura entre a vida cotidiana e o lançamento do homem ao mundo irracional, assim, os sepultamentos deixam de acontecer nas igrejas e passam a ocorrem em cemitérios, distantes da cidade, distante da vida real. Assim, a morte tão temida não é a morte de si mesmo, mas a morte do outro. E, contemporaneamente,

\section{POLÊM!CA $\mid$ LABORE}


não se morre mais com a família, mas em hospitais, assim como o velório também deixou as casas para ocorrerem nos próprios cemitérios, e com o menor tempo de duração possível. A morte deve ser evitada, negada. Deve ficar nas representações de Luz e Sombra.

Assim, cerimônias estão cada ver mais curtas, como também se observa, segundo Caputo (2008), um encurtamento dos períodos de luto. A sociedade passa a privilegiar a preservação da felicidade e não há espaço para sofrimento e nem para a vivência do luto. Uma participante (12), lembrando uma cena do filme, afirmou: ".. a mãe não deveria escrever as cartas para as filhas nos seus aniversários, por que ela estava renovando o sofrimento a cada aniversário das meninas, isso é trazer o sofrimento todo ano." Outro participante (15) descreveu que "... não vejo necessidade em velar o morto a noite toda, não tem sentido isso, é ficar sofrendo à toa, deveria enterrar imediatamente." E mais uma outra participante relatou que queria apenas ser cremada e jogadas suas cinzas e que não queria choro. Todas essas atitudes afastam o homem da angústia da morte, porque o morrer do outro mostra a sua própria finitude e que deve ser evitada. Assim, o sofrimento deve ser evitado a qualquer custo, como disse o participante 14 ".... a morte traz muita sofrência."

Os participantes que defenderam as representações da morte como Espelho e Nada afirmaram que "... o sofrimento é importante, porque traz novos sentidos para quem fica" (Participante 4). Já o participante 1 afirmou que "... hoje quase não se tem mais luto, as pessoas não querem mais sofrer, elas terceirizaram o sofrimento." Essa ideia foi complementada pelo participante 20 que defendeu que "... as pessoas não querem mais entrar em contato com a sua dor." E finalmente, pode-se concluir, na fala do participante 9, sobre o processo de ritual, que "... a morte antes era mais simbólica, hoje percebe-se uma banalização da morte"

\section{O Cuidar e o que Fazer diante do Morrer}

Mas como deveria ser, então, a postura de quem passa por experiências de morte? Como ela deve se cuidar e cuidar do outro? Essas questões nortearam algumas reflexões, que foram categorizadas em duas dimensões: o cuidar próprio e o cuidar do outro.

Mais uma vez os participantes que representaram a morte com Sombra e Luz tiveram posicionamentos diferentes dos que a representaram com Espelho e Nada. Os que a viram como Sombra, argumentaram sobre o medo, resumindo na fala de uma participante (não

\section{POLÊM!CA $\mid$ LABORE}


identificada na gravação) "... as pessoas não estão preparadas para morrer e por isso vivem se cuidando, fazendo dietas, plásticas. Assim o viver se torna lucrativo!". Para os que viram como Luz, afirmaram, resumindo na fala do participante 12: "... deve buscar oração e arrependimento e se conformar com a morte, porque haverá outra vida, melhor. Logo a postura é de se aceitar, resignar-se e arrepender-se."

Para os que representaram como Espelho e Nada, revelaram algumas reflexões, listadas no Quadro 3

Quadro - 3: Percepções sobre as atitudes diante da Morte e do Morrer

"... para quem está hospitalizado, agoniando, o ideal não é dizer que está tudo bem, mas deixar o paciente chorar, colocar toda a emoção para fora, para que consiga se reorganizar." (Participante 4)

"... a dor é singular, o pai de uma amiga faleceu e ela repetia: é meu pai, como se dissesse "é minha dor" (Participante 9).

"... hoje há uma maior negação da morte, parece ser vergonhoso ter que chorar, principalmente para os homens, deve-se eliminar a culpa social." (Participante 12)

"Deve-se cuidar da dor do outro com respeito, acolhimento do sofrimento dele e do seu próprio, deve-se buscar um luto mais humanizado e menos banal." (Participante 15)

"deve-se buscar sua representatividade e significado para cada pessoa. É viver a dor que faz parte da vida e sem culpa (Participante 17).

Percebe-se, analisando o Quadro 3, que as pessoas que possuem maior aceitação diante do seu próprio morrer, compreendendo sua finitude, acreditam que as pessoas devem viver o luto, sem medo, sem preconceito, entendendo-o como um processo natural e que faz parte da vida.

\section{Considerações Finais}

O objetivo do trabalho foi investigar as percepções dos jovens acadêmicos de psicologia sobre a morte e o morrer. As investigações fenomenológicas demonstraram um possível percurso rumo à busca da apropriação do seu próprio morrer, segundo Heidgger (1996), metaforicamente indo da luz (negação por meio da crença além morte), passando para sombra (evitação da dor e sofrimento), espelhando a própria morte (reconhecendo o seu próprio morrer) até ao nada e a possibilidade de refletir sobre as ilusões vivenciadas para evitar a própria morte, silenciando-as e libertando o homem para suas escolhas mais autênticas.

\section{POLÊM!CA $\mid$ LABORE}

Polêmica - Revista Eletrônica da Uerj - Rua São Francisco Xavier, 524, $1^{\circ}$ andar bloco D, sl.1001 • Tels.: +55 21 2334-4088/4087 • http://www.e-publicacoes.uerj.br/index.php/polemica/index http://www.labore.uerj.br • laboreuerj@yahoo.com.br 
Os estudos revelaram ainda a importância do cuidar e o fazer diante da morte, explicitando a importância de se vivenciar o luto e a preparação do homem para lidar com sua finitude, devendo, para isso, ser respeitada a dor do outro, mas sem buscar atalhos para essa dor. É buscar acolhimento, eliminar a culpa social e revelar os novos sentidos que o processo poderá trazer na vida de quem fica.

Esse estudo possui, entretanto, algumas limitações metodológicas. A primeira delas diz-se da amostra, focada na percepção de jovens universitários, a maioria de classe média e que estão em um momento de existência que os levam a uma negação natural da morte e do morrer. A outra limitação dessa da investigação de cunho apenas qualitativo, revelando a necessidade de investigações mais abrangentes, considerando as realidades culturais e diversas do país.

Sugere-se a partir dessas limitações, ampliar a pesquisa para pessoas de outras faixas etárias, considerando suas realidades socioeconômica e culturais, bem como, se possível, realizar investigações quantitativas, verificando se é possível a quantificação dessas percepções sobre a morte e o morrer.

\section{Referências}

ARIÈS, P. História da morte no ocidente. Rio de Janeiro: Ediouro, 2003

CAPUTO, R. F. O Homem e Suas Representações sobre a Morte e o Morrer. São Paulo, Saber Acadêmico, nº 6, 2008.

FRANKL, V. E. Psicoterapia para todos: Uma psicoterapia coletiva para contrapor-se à neurose coletiva (A. Allgayer, Trad.). Petrópolis: Vozes, 1990.

GASKELL, G. Entrevistas individuais e grupais. In: GASKELL, G.; BAUER, M. W. (Org.). Pesquisa qualitativa com texto, imagem e som: um manual prático. Petrópolis: Vozes, 2002.

GILES, T. R. História do existencialismo e da fenomenologia. São Paulo: EPU, 1989.

GOMES, W. B. A entrevista fenomenológica e o estudo da experiência consciente. In: GOMES, W. B. (Org.). Fenomenologia e pesquisa em psicologia. Porto Alegre: Editora da Universidade/UFRGS, 1998.

HEIDEGGER, M. (1988). Ser e Tempo (Parte I). Petrópolis: Vozes, 1988.

HEIDEGGER, M. Que é Metafísica? Os pensadores. São Paulo: Nova Cultura, 1996.

HEIDEGGER, M. Ser e Tempo. Vol. 2. Trad. Márcia de Sá Cavalcante. 5ª Ed. Petrópolis RJ: Vozes, 1997.

HUSSERL, E. Ideas relativas a una fenomenología pura y una filosofia fenomenológica. México: Fondo de Cultura Econômica, 1992.

\section{POLÊM!CA $\mid$ LABORE}


KOVÁCS, M. J. Morte e desenvolvimento humano. São Paulo: Casa do Psicólogo, 1992.

KÜBLER-ROSS, E. Sobre a Morte e o Morrer. São Paulo: Martins Fontes, 1996.

LANIGAN, R. L. Phenomenology of communication. Pittsburgh, PA: Duquesne University Press, 1988.

SOUZA, M. A. A Angústia, o nada e o sentido da vida em Heiddeger. Disponível em: < https://filosofonet.wordpress.com/2014/04/27/a-angustia-o-nada-e-o-sentido-da-vida-3> Acesso em: 29 mai. 2015.

SPILKA, B., STOUT, L., MINTON, B., SIZEMORE, D. Death and personal faith: A psychometric investigation. Journal for the Scientific Study of Religion, n.16, p. 169-178, 1977.

Recebido em: 19/07/2016.

Aceito em: 14/09/2016.

\section{POLÊM!CA $\mid$ LABORE}

Polêmica - Revista Eletrônica da Uerj - Rua São Francisco Xavier, 524, $1^{\circ}$ andar bloco D, sl.1001 • Tels.: +55 21 2334-4088/4087 • http://www.e-publicacoes.uerj.br/index.php/polemica/index http://www.labore.uerj.br • laboreuerj@yahoo.com.br 